\title{
Management of Avulsed Tooth by Inter Disciplinary Endo-Perio Approach- A Case Series
}

\author{
Joshi Bharat* \\ Swami devi dyal dental college and Hospital Barwala, India
}

Received: December 13, 2017; Published: March 22, 2018

*Corresponding author: Bharat Joshi, Set No 116, Phase 3, HIG Himuda colony, Baddi, tehsil Nalagarh, Distt. Solan, Himachal Pradesh, Pin code 173205, India, Tel: 07831880064; Email: bharatrimpu@gmail.com

\begin{abstract}
Among widespread oral diseases, endo-perio lesions carry a special weight age in terms of identification and prognosis. The tooth mortality rate among these clinical conditions is close to $50 \%$ and etiological factors were also variable. These conditions are very difficult to diagnose since the etiological factors vary from individual to individual. The symptoms are often intermixed and sometimes are totally asymptomatic. Management remains a formidable task for clinicians because success rate is difficult to determine and prognosis depends upon the involvement and progression of lesion. Another worry for the clinicians is whether early re-implantation is necessary or late reimplantation could be performed if immediate storage medium of avulsed tooth is not available. In this paper, a case series has been depicted in which two combined endo- perio lesions avulsive in nature were successfully managed. Earlier endodontic treatment was performed followed by periodontal therapy. Excellent results were obtained in terms of esthetics and phonetics and there were no post-operative complications.
\end{abstract}

Keywords: Avulsion; Endo-perio; Flap; Splinting; Endodontic Therapy

\section{Introduction}

Oral diseases comprises of vast array of diseases ranging from acute dental caries to chronic periodontitis. Both the endodontium and periodontium are closely related with each other and it is quite possible that, diseases of one tissue may affect and progress another tissue. Often patient presents with localized pain restricted to one tooth only, but sometimes, secondary etiology is also there. The differential diagnosis of endodontic and periodontal diseases is practically not so easy but is of foremost importance and therefore, appropriate treatment is must. The relationship between periodontal and pulpal disease was first explained by Simring and Goldberg [1] while Turner and Drew described the effect of periodontal disease on the pulp [1,2]. Since then, the term 'perioendo lesion' has been subsequently used to describe lesions due to inflammatory products [3]. There are certain etiological factors like bacteria, fungi and viruses whereas contributing factors like trauma, root resorption, perforations and dental malformations play a pivotal role in the development and progression of such conditions [3]. It has been observed that pulpal and periodontal problems cause about $50 \%$ of tooth mortablity [4]. Hence, these should be taken into account with proper care and knowledge.

This paper presents two different endo-perio lesions which were both associated with avulsion. Both the cases were first managed by complete endodontic therapy followed by periodontal therapy. 1st case was associated with deep periodontal pocket and abscess drainage while second one was non-vital in nature. After endodontic therapy and flap surgery, Temporary Splinting was done for two weeks followed by permanent inter-coronal splinting. Follow-up was done for 1, 3, 6 \& 12 months. There were no postoperative complications and, esthetics was also maintained. Patients were also able to carry out normal routine chewing and, phonetics was also not affected.

\section{Case Report}

\section{Case 1}

A 24 years adult old male came to the Department of Periodontology, Bhojia dental college \& Hospital, Baddi, with a chief complaint of continues discharge and moving tooth. On clinical examination, it was noticed that there was abscess drainage and grade 3 mobility with respect to left maxillary central incisor (tooth no.-21) (Figure 1). On probing, $7 \mathrm{~mm}$ pocket depth was noticed and supra-gingival calculus was also present. Tooth was vital and tender on both vertical and lateral percussion. Radiographic examination revealed vertical bone defect (Figure 2). It was classified as class IV endo-perio lesion [5] Patient wanted to preserve the tooth and was not interested in any prosthesis (removable or fixed). It was decided to perform endodontic therapy (Root canal treatment) followed by flap surgery with bone graft and splinting. Full mouth scaling and root planing was done by hand and ultrasonic instruments, at least 
4-5 weeks prior to the surgery and oral hygiene instructions were given and reinforced at each visit. After completion of endodontic therapy, temporary splint was given for two weeks and patient was scheduled for surgical phase (Figures 3 \& 4).

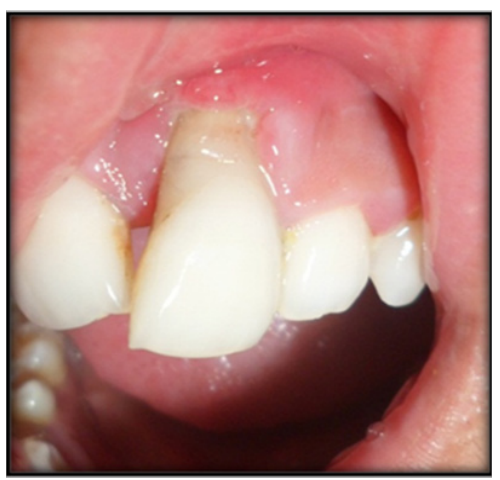

Figure 1: Pre-operative view showing no. 21.

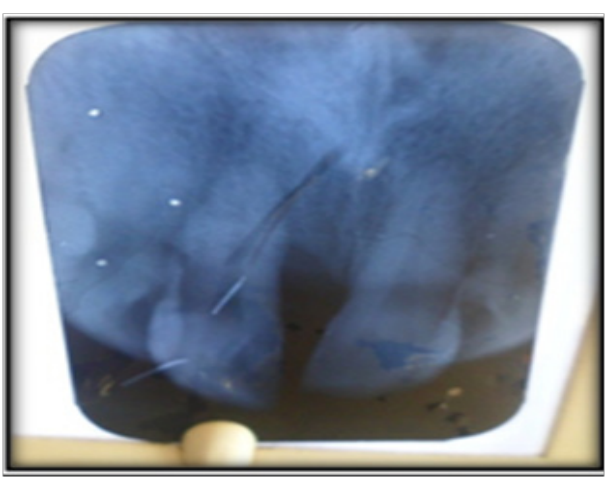

Figure 2: Radiograph showing vertical extruded tooth bone loss with respect to tooth no. 21 .
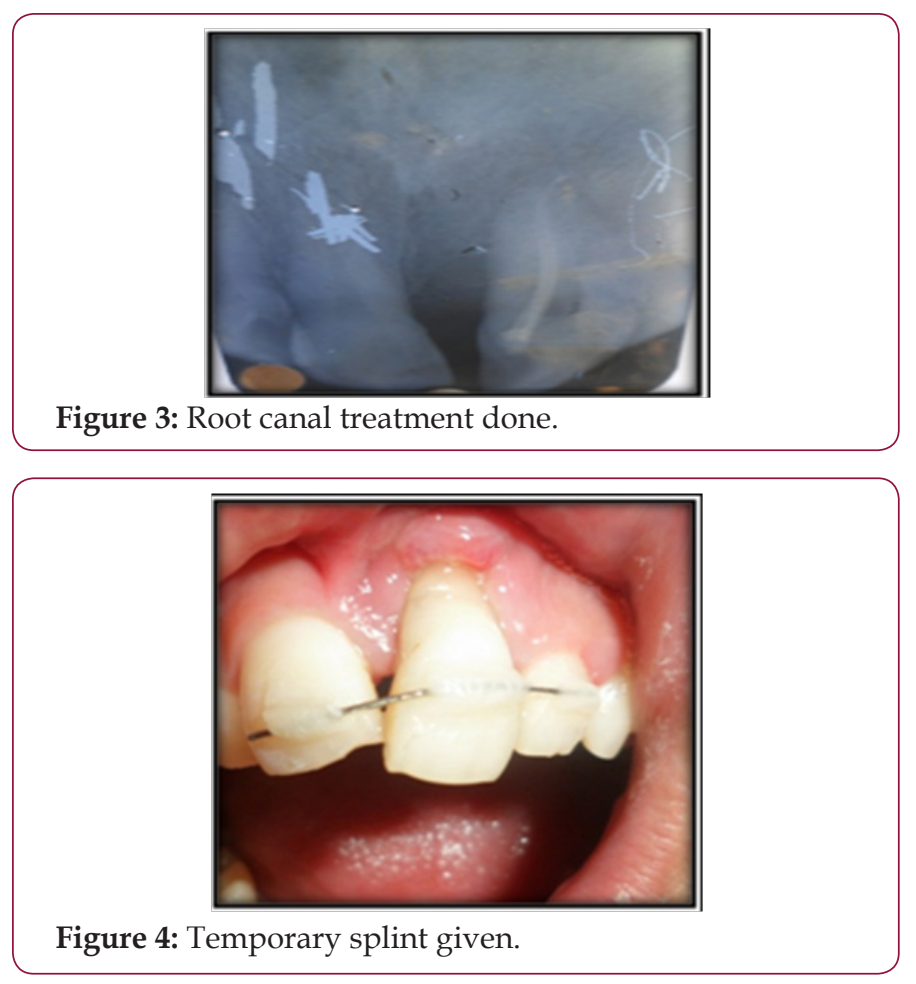

Investigation: Complete radiographspre \& post-operative (IOPA) were recorded to ensure success of the involved teeth (Figures 2-14). Impressions were also recorded to eliminate preoperative occlusal pre-maturities (Figure 11).

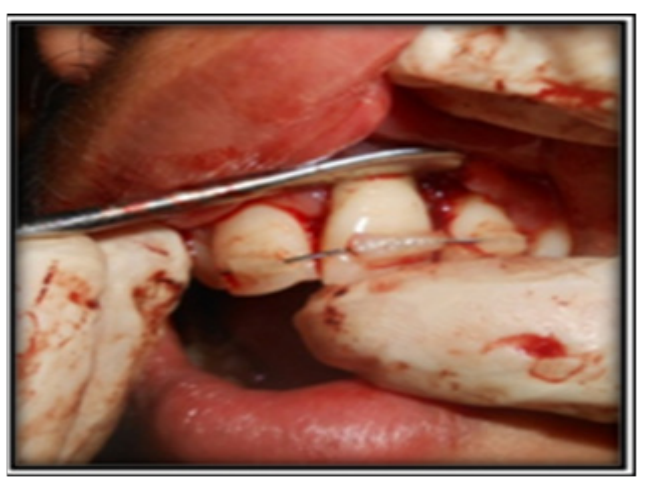

Figure 5: Flap raised and debridement done.

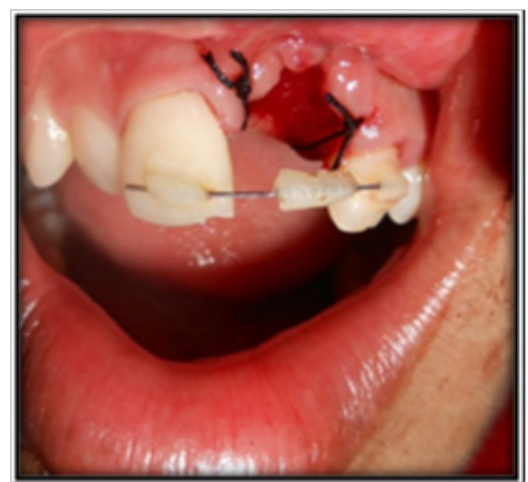

Figure 6: Sutures given after avulsion of tooth no.21.

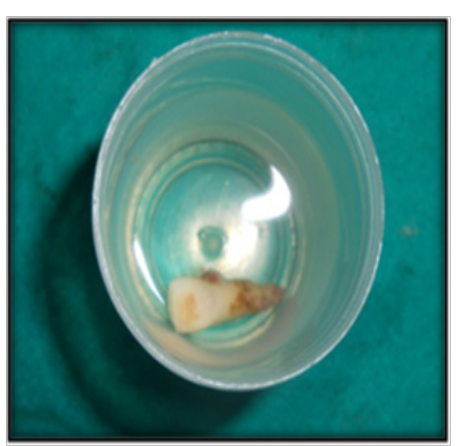

Figure 7: Avulsed tooth placed in saline.

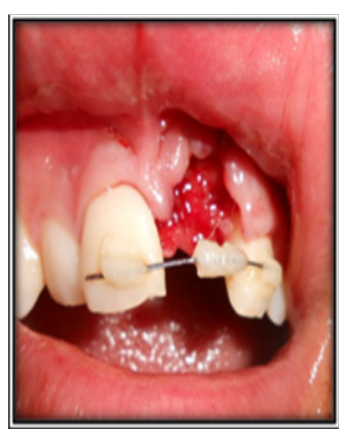

Figure 8: Post-operative, 2 weeks. 


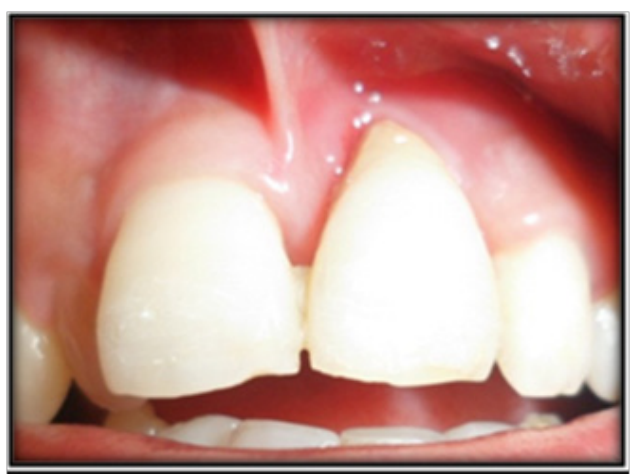

Figure 9: Tooth no. 21 permanently splinted to adjacent teeth.

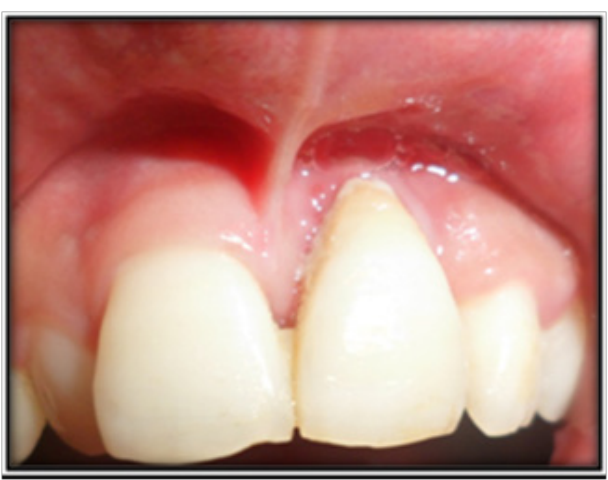

Figure 10a: 6 months post-operative.

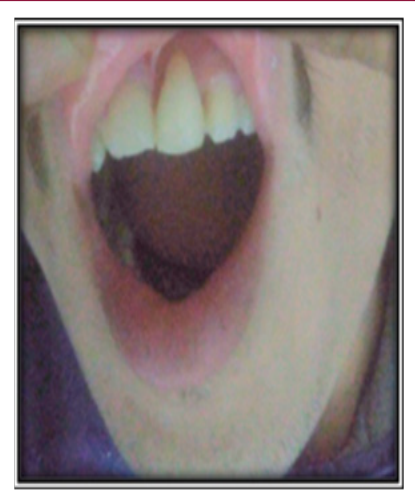

Figure 10b: 1 year post-operative.

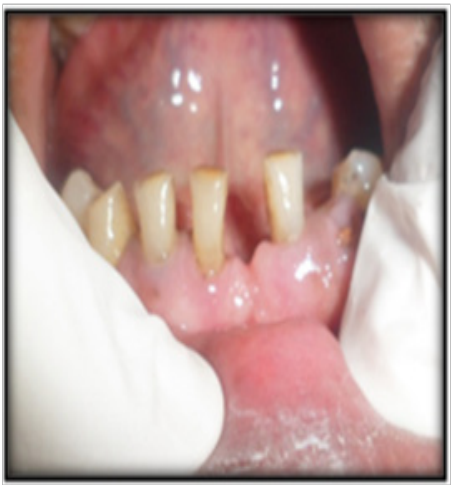

Figure 11: Traumatic injury to tooth no. 31 causing avulsion.

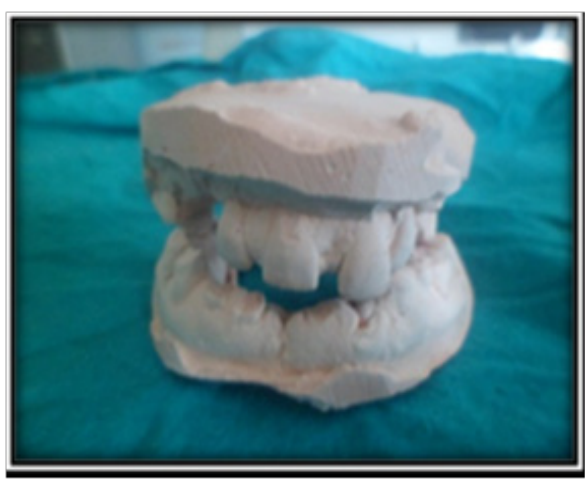

Figure 12: Impressions for occlusal adjustment.

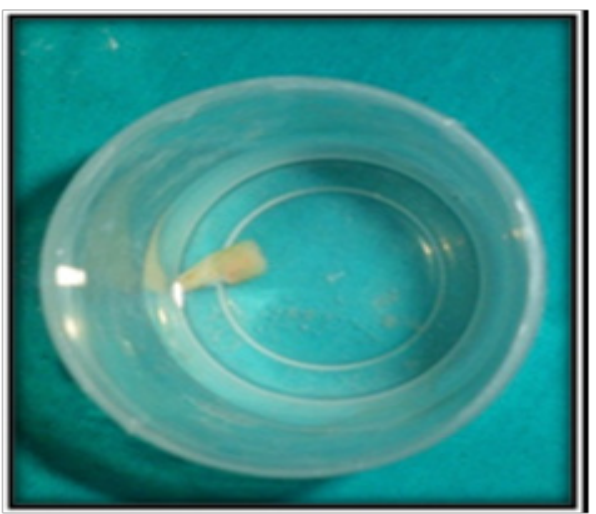

Figure 13: Avulsed tooth placed in saline.

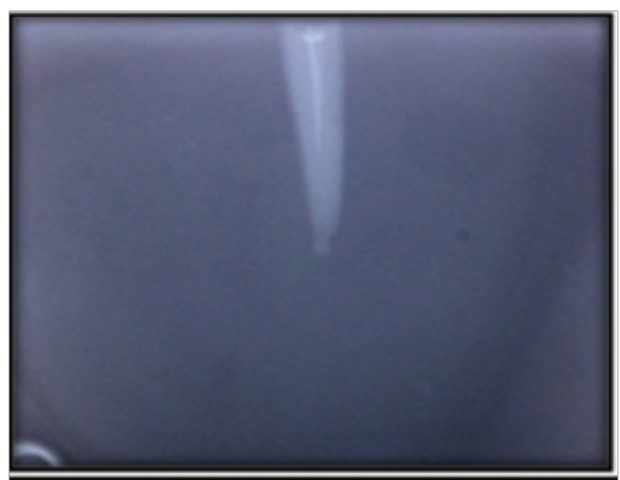

Figure 14: Root canal treatment of avulsed.

Surgical Phase: After proper blood investigations, the patient was given written and verbal information on the nature, risks and benefits of the surgical procedure and a signed, informed consent was obtained prior to the treatment .After giving adequate local anaesthesia [2\% lignocaine hydrochloride with adrenaline 1:200000], using No. 12 Bard Parker blade, crevicular incisions were given and a full-thickness flap was elevated. After proper mechanical debridement with curettes and scalers, graft (allograftDFDBA) was applied on the defect and flap was closed with 2 interrupted (3-0) mer silk sutures (Figures 5 \& 6). Patient was recalled after 1 week for permanent splinting (Ligature wire with light cure) as there was a lot of necrotic cementum and calculus and coincidentally, no medium was available for storage of avulsed 
tooth (Figures $7 \&$ 8). Patient was recalled after 1, 2 weeks and 3, 6 $\& 12$ months. There was uneventful healing and excellent esthetics, were maintained (Figures $9 \& 10 a, b$ ).

\section{Case 2}

A 55 years old adult male came to the Department of Periodontology, Bhojia dental college \& Hospital, Baddi, with a chief complaint of discomfort due to trauma. On clinical examination, it was noticed that there was grade 3 mobility and mild supra-gingival calculus with respect to left mandibular central incisor (tooth no.31). However, tooth became avulsed and was held in mouth by patient's own support (Figure 11). Tooth was vital and tender on vertical percussion. It was classified as class III endo-perio lesion [6]. This patient also wanted to preserve the tooth and was not interested in any prosthesis (removable or fixed). It was decided to perform endodontic therapy (Root canal treatment) followed by splinting. Apical portion was also trimmed off. Full mouth scaling was done by hand and ultrasonic instruments and after completion of endodontic therapy, tooth was splinted with permanent splint (Ligature wire with light cure) (Figures 13-15).

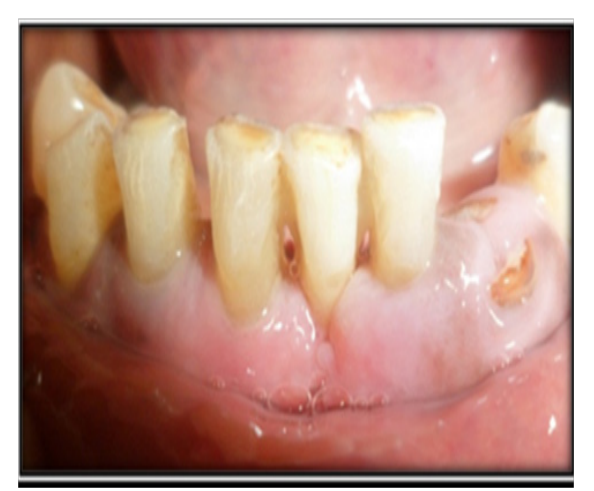

Figure 15: Intra-coronal splinting done with respect to tooth no. 31 .

\section{Results}

Pre-operative pocket depth decreased to $3 \mathrm{~mm}$ from $7 \mathrm{~mm}$ in 1 st case .Also, phonetic was not affected. In the second case also, esthetic were maintained and phonetics were not affected.

\section{Discussion}

Endo-perio lesions remain a dilemma for both endodontists and Periodontists. They are very difficult to diagnose as the progression of lesion varies from individual to individual. Both Endontium and periodontium are related in that fashion that infection of one can spread and involve another tissue [6]. With the occurrence of necrosis inside the pulp chamber, an inflammatory response evokes which is initiated by periodontal ligament through apical foramen and at the opening of the accessory canals and, it results in rapid and wide spread destruction of periodontium, formation of radiolucency at the apex of the tooth, in the furcation or at certain anatomic locations along the root [7]. It has been shown that periodontal treatment of teeth with pulpal necrosis and periapical radiolucency resulted in retarded or impaired periodontal healing [8]. Retrograde periodontitis which is often caused by pulpal disease is a common cause of severe, localised destruction of periodontal tissues.

The signs and symptoms are characterized by periodontal pocket formation, purulent inflammatory exudates, and angular bone loss, swelling, bleeding of the gingival tissues and increased tooth mobility $[9,10]$. A greater incidence of pulpal inflammation and degeneration has been reported in periodontally involved teeth than in teeth with no periodontal disease [11]. But, it has been suggested that periodontal disease has no effect on the pulp till it involves the apex or the periodontal breakdown has exposed an accessory canal to the oral environment $[12,13]$. Therefore, theoretically a deleterious effect of periodontal disease on the pulp can occur and produce pulpitis and is often referred as retrograde pulpitis [1]. Microbes too play an important role in progression of endo-perio lesions. Actinobacillus actinomycetemcomitans, bacteroides frosythus, Ekinella corrodens, Fusobacterium nucleatum, Porphyromonas gingivalis, Prevotella intermedia and Treponema denticola are among those present in both endodontic samples and in cases of chronic apical \& adult periodontitis [14]. Various fungal species namely Candida albicans are prevalent both in endodontic infections as well as in many cases of adult periodontitis (in sub-gingival environment) $[15,16]$.

Viruses are also not lagging behind in causing endo-perio infections. Recent data suggests that a number of common types of viruses especially Cytomegalo virus, Epstein-Barr virus, herpes virus may be involved in pathogenesis of periodontal and endodontic disease ranging from an increase in periodontal pathogens in periodontal pockets to involvement in pulpal and peri-apical pathologies [17-19]. Identification of endo-perio lesion remains the key for successful treatment. The two cases which were treated had different etiological factors. First case was associated with recurrent abscess formation and on clinical examination; $7 \mathrm{~mm}$ pocket depth was found. It was primarily perio and secondarily endo lesion. (Class IV) [5]. There was also grade 3 mobility. As a general rule, the success of a periodontal therapy in combined endo-perio cases is determined by successful endodontic therapy [6]. After completion of endodontic therapy, temporary splinting was performed for 15 days. After 15 days, flap surgery was performed to eliminate pocket. During flap surgery, tooth became avulsed due to complete elimination of sub-gingival calculus and necrotic cementum. It was not possible to immediate lyre-implant the tooth since there was a lot of bleeding from soft tissues.

It is suggested that with late implantation, removal of necrotic periodontal ligament remnants must be done properly and certain agents may be applied to resist root resorption such as sodium floride, stannous fluoride, tetracycline, citric acid, hypochloric acid, calcium hydroxide, formalin, alcohol, diphosphonates \& indomethacin [20] Fluoride is useful in acting on cementum, thereby, converting hydroxyapatite to a more resistant substance, fluorapatite and is successful in inhibiting microbial growth and metabolism. 19It also has a specific inhibitory action on the clastic cells. Hence, when there was complete healing, permanent intracoronal splint (ligature wire) was given and tooth was again re- 
implanted. Second case was also vital in nature with generalized bone loss (physiological) and grade 2 mobility but tenderness was present with only vertical percussion. There was no pocket depth .It was primarily endo and secondarily perio (class III) [5]. After completion of endodontic therapy, it was splinted with permanent splinting (intra-coronal). It was immediately re-implanted because the time duration was less than 15 minutes and according to standard protocols, the time duration for ideal re-implantation ranges between 20-30 minutes [21,22]. As the bone loss was physiological in nature with minimal pocket depth $(2 \mathrm{~mm})$, no flap surgery was performed in this case. Both these cases were managed with different techniques since the etiology, sign and symptoms were different for both of them. But the results achieved demonstrated that both the techniques were appropriate for these lesions.

\section{Conclusion}

There is still a controversy about management of avulsed endoperio lesions. But in my opinion, if standard protocol is followed, both immediate and late re-implantations can be successful. It is the duty of clinician to first identify and then determine the treatment plan and prognosis of avulsed endo-perio cases.

\section{References}

1. Simring M, Goldberg M (1964) The pulpal pocket approach: retrograde periodontitis. J Periodontol 35(1): 22-48.

2. Peeran SW, Thiruneervannan M, Abdalla KA, Mugrabi MH (2013) EndoPerio Lesions. IJSTR 2(5): 268-274.

3. Singh P (2011) Endo-Perio Dilemma: A Brief Review. Dental Research Journal 8(1): 39-47.

4. Chen SY, Wang HL, Glickman GN (1997) The influence of endodontics treatment upon periodontal wound healing. J Clin Periodontol 24(7): 449-456.

5. Simon JHS, Glick DH, Frank AL (1972) The relationship of endodonticperiodontal lesions. J Peridontol 43(4): 202-208.

6. Newman MG, Klokkevold PR, Takei HH, Carranza FA (2014) Carranza's clinical Periodontology. $11^{\text {th }}$ (Edn.). Saunders Elsevier, Missouri, USA.

7. Seltzer S, Bender IB, Nazimov H, Sinai IP (1967) Pulpitis-induced interradicular periodontal changes in experimental animals. J Periodontol 38(2): 124-129.
8. Ehnevid H, Jansson LE, Lindskog SF, Blomlöf LB (1993) Periodontal healing in relation to radiographic attachment and endodontic infection. J Periodontol 64(12): 1199-1204.

9. Clarke NG (1990) Periodontal defects of pulpal origin: Evidence in early man. American Journal of Physical Anthropology 82(3): 371- 376.

10. Clarke NG, Hirsch R (1992) Two critical confounding factors in periodontal epidemiology. Community Dent Health 9(2): 133-141.

11. Bender IB, Seltzer S (1972) The effect of periodontal disease on the dental pulp. Oral Surg 33(3): 458-474.

12. Czarnecki RT, Schilder H (1979) A histologic evaluation of the human pulp in teeth with varying degrees of periodontal disease. J Endod 5(8): 242-253.

13. (1974) Langeland. Oral Surg Oral Med Oral Pathol 34: 357.

14. Rupf S, Kannengiesser S, Merte K, Pfister W, Sigusch B, et al. (2000) Comparison of profiles of key periodontal pathogens in theperiodontium and endodontium. Endo Dent Traumatol 16(6): 269-275.

15. Hannula J, Saarela M, Alaluusua S, Slots J, Asikaainen S (1997) Phenotypic and genotypic characterization of oral yeasts from Finland and the United States. Oral Microbiol Immunol 12(6): 358-365.

16. Slots J, Rams TE, Listgarten MA (1988) Yeasts, enteric rods and pseudomonas in the subgingival flora of severe adult periodontitis. Oral Microbiol Immunol 3(2): 47-52.

17. Sabeti M, Simon JH, Nowzari H, Slots J (2003) Cytomegalo virus and Epstein-Barr virus active infection in periapical lesions of teeth with intact crowns. J Endod 29(5): 321-323.

18. Contreras A, Nowzari H, Slots J (2000) Herpes viruses in periodontal pocket and gingival tissue specimens. Oral Microbiol Immunol 15(1): 15-18.

19. Singh B, Joshi B (2016) Viruses and periodontitis.-a Review. Int J Dent Health Sci 3(4): 1183-1188.

20.Gungor OE (2016) Dental Avulsions: If Immediate Replantation was Impossible. iMedPub Journals 1: 1.

21. Andreasen JO, Andreasen FH, Andreasen L (2007) Textbook andcolor atlas of traumatic injuries to the teeth. ( $4^{\text {th }}$ Edn.), Blackwell Munksgaard, Australia, UK.

22. Flores MT, Andersson L, Andreasen JO, Bakland LK, Malmgren B, et al. (2007) Guidelines for the management of traumatic dentalinjuries. II. Avulsion of permanent teeth. Dent Traumatol 23(3): 130-136.

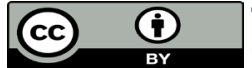

This work is licensed under Creative Commons Attribution 4.0 License

Submission Link: https://biomedres.us/submit-manuscript.php

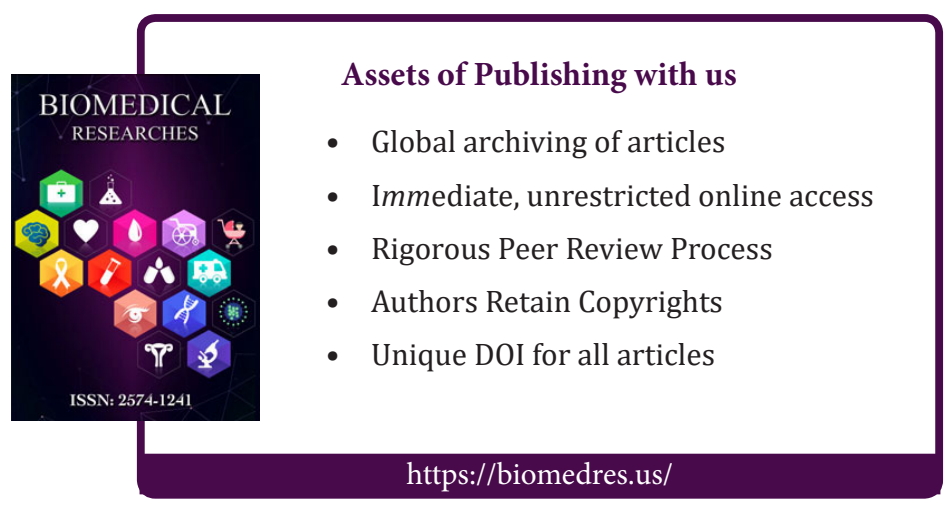

